\title{
Comparison of Bolton's Ratio for Evaluation of Tooth Size Discrepancy between Maxillary and Mandibular Arches in Vidarbha Population
}

\author{
Vikrant V. Jadhav ${ }^{1}$, Vasudevan S. D. ${ }^{2}$, Ranjit Kamble ${ }^{3}$, Meenakshi M. Tiwari ${ }^{4}$
}

\begin{abstract}
${ }^{1}$ Department of Orthodontics and Dentofacial Orthopaedics, SPDC, Sawangi, Wardha, Maharashtra, India. ${ }^{2}$ Department of Orthodontics and Dentofacial Orthopaedics, SPDC, Sawangi, Wardha, Maharashtra, India. ${ }^{3}$ Department of Orthodontics and Dentofacial Orthopaedics, SPDC, Sawangi, Wardha, Maharashtra, India. ${ }^{4}$ Department of Orthodontics and Dentofacial Orthopaedics, SPDC, Sawangi, Wardha, Maharashtra, India.
\end{abstract}

\section{ABSTRACT}

\section{BACKGROUND}

Bolton's ratio is an indispensable parameter used in orthodontic diagnosis to evaluate the tooth size discrepancy. However, these norms have been established for Caucasian population and population variations necessitate the evaluation of these ratios for Vidarbha population. The objectives of the present study were to determine Bolton's ratio for Vidarbha population, compare them with original Bolton's ratios and determine the clinical significance of these differences.

\section{METHODS}

The study sample consisted of study casts of 300 subjects in the age range of 18-30 years, all belonging to Vidarbha population, having a full complement of teeth. Tooth dimensions were measured using digital vernier caliper and Bolton's overall ratio and anterior were calculated. The data calculated was statistically analysed for range, mean, standard deviation and coefficient of variation. Unpaired t-test was applied to draw a difference between the results of this study and the results from Bolton's study.

\section{RESULTS}

Bolton's overall and anterior ratio norms for Vidarbha population sample were found to be 88.15 and 78.50, respectively, with standard deviation of 3.27 and 3.19, respectively. The range of overall ratio noted was $80.36-98.44$, and the range of anterior ratio was 67.74-89.70.

\section{CONCLUSIONS}

In general, the values obtained from this study for the Vidarbha population differ from the data of Caucasian population. So, it can be inferred that the established Bolton's values for Caucasians cannot be used for the Vidarbha population. Hence, population specific standards are necessary for clinical assessment.

\section{KEY WORDS}

Bolton's Ratio, Digital Vernier Caliper, Mesiodistal Width, Anterior Ratio, Overall Ratio, Vidarbha Population
Corresponding Author: Dr. Vikrant V. Jadhav,

JR 3, Department of Orthodontics \& Dentofacial Orthopaedics, SPDC, Sawangi, Wardha, Maharashtra, India.

E-mail: vikrantjadhav9405@gmail.com

DOI: $10.14260 /$ jemds/2020/364

Financial or Other Competing Interests: None.

How to Cite This Article:

Jadhav VV, Vasudevan SD, Kamble R, et al. Comparison of bolton's ratio for evaluation of tooth size discrepancy between maxillary and mandibular arches in Vidarbha population. J. Evolution Med. Dent. Sci. 2020;9(21):1659-1662, 10.14260/jemds/2020/364

Submission 13-01-2020, Peer Review 03-05-2020 Acceptance 11-05-2020, Published 25-05-2020.

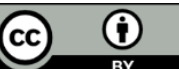




\section{BACKGROUND}

The success of orthodontic treatment depends on careful approach of record taking and diagnosis. One of the important diagnostic tools is the use of diagnostic model for estimation of tooth size. Tooth size must be proportionate to jaw size so as to avoid tooth size arch length discrepancy. The tooth size of upper and lower arch should be in ratio to achieve proper inter-digitation and occlusion.

Any deviation from a normal or "ideal" occlusion is termed as malocclusion.(1) Bennett and McLaughlin(2) added a seventh key "tooth size". Teeth should be in proper proportion to achieve acceptable occlusion. A tooth size discrepancy/disproportion (TSD) is a disparity between different the sizes of teeth, which will ultimately affect fulfilment of good occlusion. There are many studies suggesting about the methods of defining and measuring TSD. ${ }^{(3-6)}$ one among them is Bolton's ratio, which was established in 1958 by Wayne Bolton.(7) For estimating TSD, Bolton developed two ratios i.e. anterior ratio and overall or total-arch ratio. It is accepted worldwide but, its application in our population is questionable. Lundstrom( ${ }^{(6)}$ reviewed the European literature for TSD and concluded that there was genetic predisposition in the measurements of mesiodistal width of tooth size and hence could not be applied to all populations.

The associations between the dimensions of the teeth of both arches should be contingent on population. This study evaluates the reliability of the existing Bolton's ratio and it will also ensure that perfect intercuspation will occur for improvement in esthetics in patients by determining the correct tooth size relationship. Proper tooth size evaluation will be done for desirable outcome of the patient. It is believed that the Bolton's ratios are essential diagnostic aid which allows the clinician to achieve good functional and aesthetic occlusion.

The term "tooth size", refers to the "mesiodistal width of the teeth". In 1902, this was first reported by G. V. Black. (8) Studies were done(3-6) to compare the tooth size between arches and have given their formulae. Studies were carried out to develop an inter-maxillary ratio analysis with the aim of focussing discrepancies in tooth size for Indian population of zones such as Telangana, Punjab, North Indian population.(9-12) Till the literature searched there was no such data found for Vidarbha population. Therefore, the following study is planned to evaluate Bolton's ratio for Vidarbha population to obtain accurate results of the case.

\section{METHODS}

Dental casts of 300 participants aged between 18 and 30 years were obtained. The sample size was determined using the mean and standard deviation values from the study conducted by Bolton.(7) The participants were selected by one operator only, and an informed consent was taken from each participant for the same. Maxillary and mandibular alginate impressions were made of the selected 300 participants and then poured in dental stone (Kaldent Dental Plaster Class III). The casts were retrieved, and bases were fabricated. This study is observation study. The sample size was derived by complete enumeration method.

Digital caliper was used to measure the mesiodistal widths of the teeth to the nearest $0.01 \mathrm{~mm}$ of these study models, and the anterior and overall ratios were calculated.

\section{Inclusion Criteria}

1. Patients in OPD with all permanent teeth fully erupted with or without third molar.

2. Patients with age 18-30.

3. Class I malocclusion present bilaterally patient will be selected for the study (clinical examination).

4. Class I canine and incisor relation bilaterally along with Andrew's six keys.

5. Good-quality study casts.

\section{Exclusion Criteria}

1. Patient with multiple missing teeth.

2. Unerupted permanent teeth.

3. Unrestored carious teeth.

4. Teeth with full coverage restoration.

5. Proximal wear/attrition of teeth.

6. Congenital defects or deformed teeth

Mesiodistal width of all the teeth from maxillary first molar of right side till the molar on contra-lateral side and mandibular first molar of right side till left side were calculated. A digital vernier caliper was used to measure the mesiodistal width of the teeth. The tips of the caliper were placed in the contact point of the tooth and the mesiodistal width of the teeth were recorded and entered into the chart shown below. All the measurements were carried out in millimeters. This was repeatedly done by the same operator for two times. Mean of the values were calculated. This mean value was used for calculation. Mean, standard deviation, range and $p$ value was calculated. The readings were used to calculate overall and anterior ratio. Bolton's ratio was analyzed using SPSS 23 version.

Following the tabulation of the teeth sizes, individual analysis was performed on each set of casts

\begin{tabular}{|llllllllllllll|}
\hline UR & 6 & 5 & 4 & 3 & 2 & 1 & 1 & 2 & 3 & 4 & 5 & 6 & UL \\
LR & 6 & 5 & 4 & 3 & 2 & 1 & 1 & 2 & 3 & 4 & 5 & 6 & LL \\
\hline \multicolumn{1}{c|}{ Teeth Sizes } & & \multicolumn{1}{c|}{} & & & & & &
\end{tabular}

The values were compared with the obtained results.

\section{Bolton's Analysis is -}

1. Overall Ratio

$$
\frac{x^{\prime}}{x} \text { or } \frac{\text { Sum mandibular } 12}{\text { Sum maxillary } 12} \times 100=\text { Overall ratio }
$$

\section{Anterior Ratio}

$$
\frac{y^{\prime}}{y} \text { or } \frac{\text { Sum mandibular } 6}{\text { Sum maxillary } 6} \times 100=\text { Anterior ratio }
$$

The values were compared with the obtained results. 
Statistical analysis showed calculation of Mean, Standard Deviation, Range and $\mathrm{p}$ value. Comparison was done between Bolton's study and present study based on overall ratio and anterior ratio. For comparison of ratios between two studies Unpaired t-test was drawn. Mean overall and anterior ratios were calculated (Table 1 and Table 2).

\section{RESULTS}

The data calculated was statistically analysed for range, mean, standard deviation and coefficient of variation. Unpaired t-test was applied to draw a difference between the results of this study and the results from Bolton's study. The mean overall and anterior ratios were found to be 88.15 and 78.50, respectively, with standard deviation of 3.27 and 3.19 , respectively. The range of overall ratio noted was 80.36-98.44, and the range of anterior ratio was 67.74-89.70. Significance difference was observed between results of Bolton's study and present study. (Table 1 and Table 2)

\begin{tabular}{|c|c|c|c|c|c|c|c|}
\hline & $\mathbf{N}$ & Mean & S.D. & Range & $\mathbf{t}$ & df & $\mathbf{P}$ \\
\hline Present Study & 300 & 88.15 & 3.28 & $80.36-98.44$ & 20.26 & 149 & $0.001^{*}$ \\
\hline Bolton's study & 50 & 91.30 & 1.91 & $87.50-94.80$ & 20.20 & 147 & 0.001 \\
\hline
\end{tabular}

The mean OR in our study was found out to be $88.15 \pm 3.28$ and when it was compared Bolton's Caucasian population, our ratio was lower, and difference was statistically significant $(\mathrm{p}<0.05)$

\begin{tabular}{|cccccccc|}
\hline & N & Mean & S.D. & Range & t & df & P \\
Present Study & 300 & 78.51 & 3.20 & $67.74-89.70$ & 9.65 & 149 & 0.001 \\
Bolton's study & 50 & 77.20 & 1.65 & $74.5-80.4$ & & & $*$ \\
\hline \multicolumn{1}{|c|}{ Table } & 2. Statistical Comparison of the Anterior Ratios \\
between the Present Study and Bolton's Results (1958) & \\
\hline
\end{tabular}

\section{Anterior Ratio (AR)}

The mean AR in our study was found out to be $78.51 \pm 3.20$ and when it was compared Bolton's Caucasian population, our ratio was higher and was statistically significant $(\mathrm{p}<0.05)$

Table of Bolton's give the descriptive statistics including the mean, standard deviation, and range of the anterior and overall ratios for the participants.

A statistically significant difference was noted in the anterior and overall ratios derived from the present study as compared to the values from Bolton's study. Both anterior and overall ratios were on the lower side.

\section{DISCUSSION}

Multifactorial aetiology has been attributed to spacing or dental crowding in permanent dentition. One such factor is the mesiodistal tooth width discrepancy.(13) The importance of TSD is very well known and recognized by orthodontist.(13)

Several studies have reported differences in mesiodistal tooth dimensions in non-crowded and crowded dentitions of different populations, by considering mesiodistal width of individual tooth rather than considering the whole arch.
Bolton(7) concluded that an overall ratio of 91.3 and an anterior ratio of 77.2 are required for good proportion of the maxillary and mandibular teeth. Bolton's evaluated 55 Caucasian females with good occlusions out of which 44 were orthodontically treated and 11 were non-orthodontically treated. Therefore, its applicability to Caucasian males and other populations was questioned. The prevalence of Bolton's TSD in different racial and malocclusion groups was studied and varying results are obtained.

On comparing three classes of malocclusion according to Angle, no significant differences was found. Therefore, only class I cases were selected.(16)

Studies done by Lavell et al(14) on Negroids population concluded that they had increased overall and anterior ratios when compared with Caucasoid and Mongoloids. Smith et al.(15)also did a study on white females and concluded that it was not applicable to white males, blacks, or Hispanics. He also observed increased overall ratio in males when compared to females. Hence, it was concluded that Bolton ratio cannot be generalised.

This study is designed to evaluate tooth width ratios in non-crowded, orthodontically untreated subjects from the Vidarbha population. A total of 300 participants aged between 18 and 30 with Angle's Class I relation, having all permanent teeth except the 3rd molar with no crowding and residual crown and bridge restorations, no tooth deformity or supernumerary teeth, and no severe mesiodistal or occlusal tooth attrition were selected for the study. Accurate dental casts of all the participants were made. Mesiodistal size of tooth were measured using a digital vernier caliper and the overall and anterior ratios were calculated.

The mean overall and anterior ratios were found to be 88.15 and 78.50 , respectively, with standard deviation of 3.27 and 3.19, respectively. The range of overall ratio noted was 80.36-98.44, and the range of anterior ratio was 67.74-89.70. (Table 1 and Table 2)

Results of the study were similar to studies done by Smith et al.(15) Therefore, now it was certain that Bolton's ratios cannot be universal. Distinct ratios for various populations are required. Further research should be done to standardize the norms for the Vidarbha population separately. These ratios are applicable to lingual orthodontics also.(17) They are can be used for paediatrics purpose also.(18-20)

\section{CONCLUSIONS}

The ratios obtained from this study for the Vidarbha population differ from the data of Caucasian population. So, it can be inferred that the established Bolton's ratio for Caucasians cannot be used for the Vidarbha population.

\section{REFERENCES}

[1] Bennett JC, McLaughlin RP. Orthodontic treatment mechanics and the pre-adjusted appliance. London: Wolfe Medical Publishing 1993. 
[2] Ballard ML. Asymmetry in tooth size: a factor in the etiology, diagnosis and treatment of malocclusion. Angle Orthod 1944;14(3):67-70.

[3] Neff CW. Tailored occlusion with the anterior coefficient. Am J Orthod 1949;35(4):309-13.

[4] Steadman SR. The relation of upper anterior teeth to lower anterior teeth as present on plaster models of a group of acceptable occlusions. Angle Orthod 1952;22:917.

[5] Lundstrom A. Intermaxillary tooth width ratio and tooth alignment and occlusion. Acta Odontol Scand 1955;12(34):265-92.

[6] Bolton WA. Disharmony in tooth size and its relation to the analysis and treatment of malocclusion. Angle Orthod 1958;28(3):113-30.

[7] Black GV. Descriptive anatomy of human teeth. $5^{\text {th }}$ edn. Philadelphia, PA: SS White Dental Manufacturing 1902: p. 37.

[8] Tonn P. Uber die mesio-distalen Zahnbreitenrelationen der Zahne des oberkieferszu den entsprechenden des unterkiefersbeinormalen and anormalen occlusion. Diss Berlin 1937.

[9] Jindal R, Bunger E. Bolton's intermaxillary tooth size ratios among school going children in Punjab population. Indian Journal of Oral Sciences 2013;4(3):110.

[10] Subbarao VV, Regalla RR, Santi V, et al. Interarch tooth size relationship of Indian population: does Bolton's analysis apply? The Journal of Contemporary Dental Practice 2014;15(1):103-7.

[11] Saritha T, Sunitha C, Kumar PK, et al. Applicability of Bolton's analysis to a South Telangana population. Indian Journal of Dental Sciences 2017;9(4):225.
[12] Patel YV, Nair VS, Jamenis SC. Bolton analysis of the Maratha population in Pune. Journal of Dental and Allied Sciences 2017;6(1):8-11.

[13] Saatci P, Yukay F. The effect of premolar extractions on tooth-size discrepancy. Am J Orthod Dentofacial Orthop 1997;111(4):428-34.

[14] Lavelle CL. Maxillary and mandibular tooth size in different racial groups and in different occlusal categories. Am J Orthod 1972;61(1):29-37.

[15] Smith SS, Buschang PH, Watanabe E. Interarch tooth size relationships of 3 populations: Does Bolton's analysis apply? Am J Orthod Dentofacial Orthop 2000;117(2):16974.

[16] Crosby DR, Alexander CG. The occurrence of tooth size discrepancies among different malocclusion groups. Am J Orthod Dentofacial Orthop 1989;95(6):457-61.

[17] Thote AM, Sharma K, Uddanwadiker RV, et al. Optimum en-masse retraction of six maxillary anterior teeth in lingual orthodontics: a numerical investigation with 3dimensional finite element analysis. Molecular \& Cellular Biomechanics 2017;14(1):1-17.

[18] Baliga SM. Indian pediatric dentistry blueprint for 2020. Journal of the Indian Society of Pedodontics and Preventive Dentistry 2018;36(4):327-8.

[19] Baliga S. A vision for pediatric and preventive dentistry oral health policy in India. Journal of the Indian Society of Pedodontics and Preventive Dentistry 2018;36(3):223-4.

[20] Baliga S. Emerging trends in pediatric dentistry. Journal of the Indian Society of Pedodontics and Preventive Dentistry 2018;36(2):107. 